\title{
Sutureless valves: A future without sutures
}

\author{
Antonio Miceli, MD, PhD, Lio Antonio, MD, and Mattia Glauber, MD
}

\author{
From the Istituto Clinico Sant'Ambrogio, Gruppo Ospedaliero San Donato, Milan, Italy. \\ Disclosures: Authors have nothing to disclose with regard to commercial support. \\ Received for publication Jan 21, 2016; accepted for publication Jan 23, 2016; available ahead of print March 5, \\ 2016. \\ Address for reprints: Antonio Miceli, MD, PhD, Istituto Clinico Sant'Ambrogio, Gruppo Ospedaliero San \\ Donato, Via Faravelli 16, 20149 Milano, Italy (E-mail: antoniomiceli79@alice.it). \\ J Thorac Cardiovasc Surg 2016;151:1627-8 \\ $0022-5223 / \$ 36.00$ \\ Copyright (c) 2016 by The American Association for Thoracic Surgery \\ http://dx.doi.org/10.1016/j.jtcvs.2016.01.038
}

The ideal prosthetic valve is easy to implant, has excellent hemodynamic performance without intrinsic thrombogenicity, and has long-term durability associated with a low risk of endocarditis. Sutureless aortic valves have demonstrated many of these characteristics; however, no data regarding long-term durability are available.

Currently, aortic valve replacement (AVR) using sutured biological valves is the conventional treatment of choice in elderly patients with severe aortic disease. This surgical approach has shown excellent outcomes and hemodynamic performance, and a very high rate of freedom from structural valve degeneration for up to 15 years. ${ }^{1,2}$ Consequently, the introduction of a new generation of prostheses is a challenge, given the excellent results achieved with the "old" valves. Nevertheless, cardiac surgery is changing. Heart surgeons are moving toward less-invasive approaches, with the aim of reducing surgical trauma. In this setting, sutureless technology represents a natural evolution.

In this issue of the Journal, Fischlein and colleagues present the 1-year results of the Cavalier Trial, an international prospective multicenter study conducted in 658 high- to medium-risk patients undergoing AVR using the Perceval S prosthetic valve. ${ }^{3}$ Specifically, they report a $4.5 \%$ incidence rate of cardiac mortality and a $3 \%$ rate of stroke. Interestingly, no cases of valve thrombosis, migration, or structural deterioration occurred, and rates of major paravalvular leakage and endocarditis were very low $(0.6 \%$ and $1.4 \%$, respectively).

These results validate the positive outcomes achieved at 30 days post-AVR, confirming that the Perceval prosthetic valve is easy to implant, safe, and associated with excellent outcomes and hemodynamic performance. ${ }^{4}$

Sutureless valves have been designed as alternatives to conventional valves to simplify surgical implantation and reduce operative time, especially in the setting of minimally invasive procedures. Available evidence suggests that the use of sutureless valves is associated with decreased operative time, ventilation time, intensive care unit stay, and hospital stay, as well as fewer postoperative complications. $^{5-9}$ In addition, compared with traditional valves, the costs are reduced by $25 \%$. $^{10}$

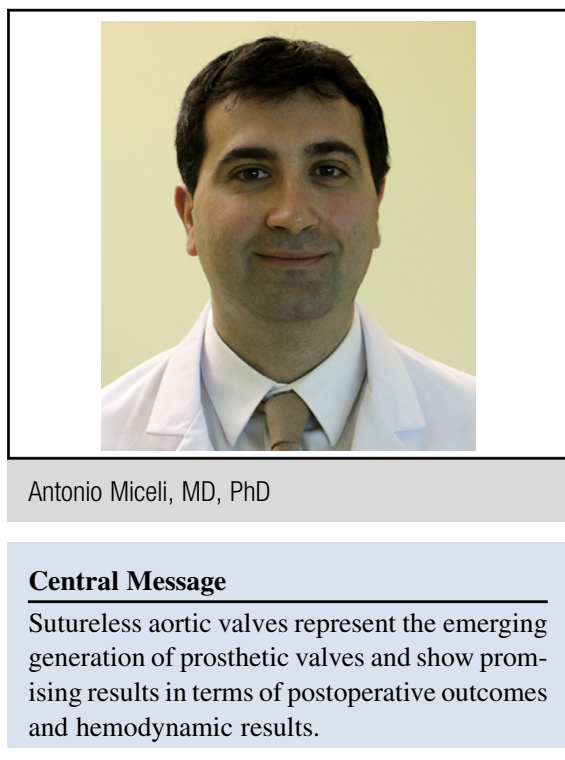

See Article page 1617 .

Despite these promising results, however, the Cavalier Trial did not address some important areas. First, no data were reported on the learning curve. In $5 \%$ of patients undergoing sutureless AVR, implantation failed due to dislodgement, malposition, paravalvular leakage, suspected aortic tear, or multiple unsuccessful attempts. These complications highlight the need for a learning curve, and the presence of a proctor is mandatory during the initial cases. We suggest conducting a specific study using CUSUM analysis to identify the number of proctored implantations required for each surgeon.

Second, the sutureless valve facilitates minimally invasive approaches; however, only $33 \%$ of cardiac procedures were performed through ministernotomy, and only 3 patients $(0.4 \%)$ had a minithoracotomy approach. Since we introduced the sutureless technology, the number of minimally invasive procedures has more than doubled. ${ }^{11}$ We previously, demonstrated that sutureless AVR through either ministernotomy or minithoracotomy is safe and reproducible, and associated with excellent postoperative outcomes and 1-year survival. ${ }^{12}$ Relative to our previous studies with stented valves, we found an overall $40 \%$ reduction in operative time. Subsequently, Dalèn and colleagues ${ }^{9}$ confirmed our results.

Third, sutureless technology speeds up the surgical procedure, reducing ischemia and cardiopulmonary machine times. In this setting, the Perceval S valve might improve surgical results, given the association between increased operative time and worse outcomes. ${ }^{13}$ These benefits should be 
more evident in patients undergoing combined procedures. Nevertheless, only $30 \%$ of patients underwent combined procedures, most of which were concomitant myocardial revascularizations. No data on multiple valve surgery have been reported. Minh and colleagues ${ }^{14}$ suggested expanding the indications for sutureless AVR to patients with mitral disease, even though it is an off-label procedure.

Fourth, in the Cavalier Trial, a bicuspid aortic valve was considered a contraindication for Perceval S prosthetic valve implantation. However, a bicuspid aortic valve is the most common congenital cardiac disease, and an estimated $50 \%$ of all valve replacement surgeries for aortic valve stenosis can be attributed to it. ${ }^{15}$ Recently, Nguyen and colleagues ${ }^{16}$ demonstrated that the Perceval valve can be deployed in patients with a type 1 bicuspid aortic valve, and we have described the technique to deal with a type 0 bicuspid valve.

Finally, the strength of a biological valve is its long-term durability. This trial has been designed to evaluate the safety and effectiveness of the Perceval valve at 12 months after implantation. A longer follow-up is required to evaluate the long-term durability of the Perceval valve. However, a large cohort of patients undergoing sutureless AVR, which includes also patients enrolled in the Cavalier Trial, have shown satisfying results up to 5 years. ${ }^{17}$

An international expert consensus panel's recently published recommendations for the use of sutureless and rapid-deployment valves state that such valves should be considered the first-line treatment option for patients with several comorbidities, patients of advanced age, or patients with aortic wall abnormalities, such as a small calcified aortic root, porcelain aorta, or previously implanted aortic homograft or stentless valves. ${ }^{18}$ These valves in combination with a minimally invasive approach might be the appropriate treatment option for high-risk operable patients and a viable alternative to transcatheter aortic valve implantations. ${ }^{19,20}$ We need more data to confirm our hypothesis; however, the future will be without suture!

\section{References}

1. Brown JM, O'Brien SM, Wu C, Sikora JA, Griffith BP, Gammie JS. Isolated aortic valve replacement in North America comprising 108,687 patients in 10 years: changes in risks, valve types, and outcomes in the Society of Thoracic Surgeons National Database. J Thorac Cardiovasc Surg. 2009;137:82-90.

2. McClure RS, Narayanasamy N, Wiegerinck E, Lipsitz S, Maloney A, Byrne JG, et al. Late outcomes for aortic valve replacement with Carpentier-Edwards pericardial bioprosthesis: up to 17-year follow-up in 1000 patients. Ann Thorac Surg. 2010;89:1410-6.
3. Fischlein T, Meuris B, Hakim-Meibodi K, Misfeld M, Carrel T, Zembala M, et al. The sutureless aortic valve at 1 year: a large multicenter cohort study. J Thorac Cardiovasc Surg. 2016;151:1617-26.

4. Laborde F, Fischlein T, Hakim-Meibodi K, Misfeld M, Carrel T, Zembala M, et al. Clinical and haemodynamic outcomes in 658 patients receiving the Perceval sutureless aortic valve: early results from a prospective European multicentre study (the Cavalier Trial). Eur J Cardiothorac Surg. 2016;49: 978-86.

5. Phan K, Tsai YC, Niranjan N, Bouchard D, Carrel T, Dapunt OE, et al. Sutureless aortic valve replacement: a systematic review and meta-analysis. Ann Cardiothorac Surg. 2015;4:100-11.

6. Santarpino G, Pfeifer S, Concistré G, Grossmann I, Hinzmann M, Fischlein T. The Perceval S aortic valve has the potential of shortening surgical time: does it also result in improved outcome? Ann Thorac Surg. 2013;96:77-81.

7. Gilmanov D, Miceli A, Ferrarini M, Farneti P, Murzi M, Solinas M, et al. Aortic valve replacement through right anterior minithoracotomy: can sutureless technology improve clinical outcomes? Ann Thorac Surg. 2014;98:1585-92.

8. Meuris B, Flameng WJ, Laborde F, Folliguet TA, Haverich A, Shrestha M. Fiveyear results of the pilot trial of a sutureless valve. J Thorac Cardiovasc Surg. 2015; $150: 84-8$.

9. Dalèn M, Biancari F, Rubino AS, Santarpino G, Glaser N, De Praetere H, et al. Aortic valve replacement through full sternotomy with a stented bioprosthesis versus minimally invasive sternotomy with a sutureless bioprosthesis. Eur J Cardiothorac Surg. 2016;49:220-7.

10. Pollari F, Santarpino G, Dell'Aquila AM, Gazdag L, Alnahas H, Vogt F, et al. Better short-term outcome by using sutureless valves: a propensity-matched score analysis. Ann Thorac Surg. 2014;98:611-6.

11. Glauber M, Gilmanov D, Farneti PA, Kallushi E, Miceli A, Chiaramonti F, et al. Right anterior minithoracotomy for aortic valve replacement:10-year experience of a single center. J Thorac Cardiovasc Surg. 2015;150:548-56.e2.

12. Miceli A, Santarpino G, Pfeiffer S, Murzi M, Gilmanov D, Concistré G, et al. Minimally invasive aortic valve replacement with Perceval S sutureless valve: early outcomes and one year survival from two European centers. J Thorac Cardiovasc Surg. 2014;148:2838-43.

13. Al-Saraff N, Thalib L, Hughes A, Houlihan M, Tolan M, Young V, et al. Crossclamp time is an independent predictor of mortality and morbidity in low- and high-risk cardiac patients. Int J Surg. 2011;9:104-9.

14. Minh TH, Mazine A, Bouhout I, El-Hamamsy I, Carrier M, Bouchard D, et al. Expanding the indication for sutureless aortic valve replacement to patients with mitral disease. J Thorac Cardiovasc Surg. 2014;148:1354-9.

15. Glauber M, Ferrarini M, Lio A, Miceli A. Dealing with a stenotic bicuspid valve: is this still an off-label procedure for a sutureless valve? J Thorac Cardiovasc Surg. 2015;150:858-9.

16. Nguyen A, Fortin W, Mazine A, Bouchard D, Carrier M, El Hamamsy I, et al. Sutureless aortic valve replacement in patients who have bicuspid aortic valve. J Thorac Cardiovasc Surg. 2015;150:851-7.

17. Shrestha M, Fischlein T, Meuris B, Flameng W, Carrel T, Madonna F, et al. European multicentre experience with the sutureless Perceval valve: clinical and haemodynamic outcomes up to 5 years in over 700 patients. Eur J Cardiothorac Surg. 2016;49:234-41.

18. Gersak B, Fischlein T, Folliguet TA, Meuris B, Teoh KH, Moten SC, et al. Sutureless, rapid deployment valves and stented bioprosthesis in aortic valve replacement: recommendations of an International Expert Consensus Panel. Eur J Cardiothorac Surg. 2016;49:709-18.

19. Miceli A, Gilmanov D, Murzi M, Marchi F, Ferrarini M, Cerillo AG, et al. Minimally invasive aortic valve replacement with a sutureless valve through a right anterior mini-thoracotomy versus transcatheter aortic valve implantation in high-risk patients. Eur J Cardiothorac Surg. 2016;49:960-5.

20. Glauber M, Miceli A. Minimally invasive aortic valve replacement with sutureless valve is the appropriate treatment option for high-risk patients and the "real alternative" to transcatheter aortic valve implantation. J Thorac Cardiovasc Surg. 2016;151:610-3. 